\title{
EXTRACTION OF GLUCOSE FROM KENAF CORE USING MILD ACID TREATMENT
}

\author{
S.M. Nurhafizah ${ }^{1 *}$, M. Maizirwan ${ }^{2}$, H. Anuar ${ }^{1}$, R. Othman ${ }^{3}$, M.N. Nur Aimi ${ }^{1}$ \\ ${ }^{1}$ Department of Manufacturing and Materials Engineering, Kulliyyah of Engineering, \\ International Islamic University Malaysia, 53100 Kuala Lumpur, Malaysia \\ ${ }^{2}$ Department of Biotechnology Engineering, Kulliyyah of Engineering, \\ International Islamic University Malaysia, 53100 Kuala Lumpur, Malaysia \\ ${ }^{3}$ Herbarium Laboratory, Kulliyyah of Architecture and Environmental Design, \\ International Islamic University Malaysia, 53100 Kuala Lumpur, Malaysia \\ *Contact: nurhafizah.seeni@gmail.com, Tel: +6012-5450687
}

\begin{abstract}
Recently, many industries are aims to reduce the usage of petroleum based product or synthetic fibre due to the increment of the environmental consciousness. This has lead to the extensive research on the natural fibre in order to produce eco-friendly product that will replace the existing petroleum based products. Natural fibre can be derived from many sources such as plants, animals or minerals. However the plant fibre such as kenaf is more desirable by most of the researcher. Kenaf or scientifically known as Hibiscus cannabinus. $L$ has a complex structure because it consists of lignin, cellulose and hemicelluloses. Due to this reason, kenaf need to undergo treatment process in order to remove lignin and hemicellulose, reduce crystallinity of cellulose and increase porosity. In this study, acid treatment method was used with several parameters process such as temperature and time for getting high yield of glucose conversion. The substantially highest glucose yield was 3.4 $\mathrm{g} / \mathrm{L}$ produced at $200{ }^{\circ} \mathrm{C}$ for 60 minutes.
\end{abstract}

\section{INTRODUCTION}

Lately, biopolymer industries are attempting to decrease the dependence on petroleum based fuels and products due to the increased environmental consciousness. This phenomenon leads to the need to replace synthetic fibre with environmental friendly and sustainable materials. The tremendous increase of production and use of plastics in every sector of our life led to huge plastic wastes. Disposal problems, as well as strong regulations and criteria for cleaner and safer environment, have directed scientific research towards eco-composite materials. Each individual among the different types of ecocomposites which contain natural fibres and natural polymers have a key role. Currently, the most viable way towards eco-friendly composites is through the use of natural fibres as reinforcement.

Naturally, plants fibres such as from kenaf have three major components which consist of cellulose, lignin and hemicellulose (Maya and Sabu, 2008). These materials caused plants fibre to have a complex structure that cannot be directly converted into end products such as ethanol and lactic acid in biopolymer industry (Ren et al., 2009; Sun and Cheng, 2002). Due to this reason, plants fibres require treatment in order to remove lignin and hemicelluloses, to reduce cellulose crystallinity as well as to increase the porosity of the materials (McMillan, 1994; Sun and Cheng, 2002; Klinke et al., 2004). There are many types of treatment process such as physical, chemical (acid and alkaline) and biological treatment however acid treatment is commonly used by many researcher. 
Sulphuric acid $\left(\mathrm{H}_{2} \mathrm{SO}_{4}\right)$ or hydrochloric acid $(\mathrm{HCl})$ is commonly utilized as the chemical for lignocellulosic material or plant fibre hydrolysis such as kenaf biomass. According to Xiang (2003) and Hamelinck (2005), there are two types of acid treatment which are mild acid treatment and concentrated acid treatment (Xiang et al., 2003; Hamelinck et al., 2005). In dilute acid treatment with concentration of 0.7 to $3.0 \%$, it requires high operating temperature around 160 to $250{ }^{\circ} \mathrm{C}$. On top of that for concentrated acid treatment, it requires high amounts of acid about $34 \%$ and this can be considered as uneconomical since it will lead to high operating costs as well as various environmental problems such as corrosion and pollution (Banerjee et al., 2010).

Kenaf also known as Hibiscus cannabinus is biennial herbaceous plant that can grow up to 20 feet (Scott et al., 2007). It contains long soft base fibres, contributing 30 to $40 \%$ of the dry weight of the stem. The central core of the stem contains a weakly disbursed pith cells surrounded by a thick cylinder of short woody fibres.

The main objectives of this study is to establish analytical method of glucose content extraction from kenaf biomass as well as to decrease the crystallinity of cellulose in order to be used in producing various end products such as lactic acid and ethanol.

\section{METHODOLOGY}

\section{Design of Experiment (DOE)}

The experiment was developed and designed by Central Composite Design (CCD) using Design Expert v6.0.8 Software to determine the optimum yield of glucose content from kenaf biomass.

\section{Sample Preparation}

Kenaf biomass was obtained from Kenaf Fibre Industry Sdn Bhd, Kelantan, Malaysia and was stored in the room temperature upon arrival. Then, it was crushed and sieved using 100 $\mu \mathrm{m}$ nylon Mesh.

\section{Hydrolysis Treatment Process}

In this process, $2 \%(\mathrm{v} / \mathrm{v})$ of sulphuric acid $\left(\mathrm{H}_{2} \mathrm{SO}_{4}\right)$ was prepared in $100 \mathrm{ml}$ working volume. The optimization process was conducted using hot plate with $100 \mathrm{rpm}$ of agitation speed and $3 \mathrm{~g}$ of kenaf biomass in order to obtain optimum glucose content by varying two parameters with three levels which are mixing time and temperature. The experiments were carried out for 11 runs with two replications based on CCD method. For the analysis of the optimization results, regression analysis was done by developing the regression equation.

\section{Total Glucose Content Analysis}

Total glucose content was analyzed using high pressure liquid chromatography (HPLC) (Agilent model 1200) comprised of a quaternary pump with auto-sampler injector, microdegassers, column compartment equipped with thermostat and a diode array detector. The column used was a ZORBAX Eclipse XDB- $\mathrm{C}_{18}$ end capped $5 \mu \mathrm{m}, 4.6 \times 150 \mathrm{~mm}$ reverse phase column (Agilent Technologies, USA) and UV detector at $210 \mathrm{~nm}$. The conditions of HPLC were mobile phase acetonitrile/phosphate $(1: 9 \mathrm{v} / \mathrm{v})$, flow rate $1.0 \mathrm{ml} \mathrm{min}^{-1}$ for 15 minutes, temperature $20^{\circ} \mathrm{C}$ and injection volume $1 \mu \mathrm{L}$. Each injection was performed in duplicate. 


\section{RESULTS AND DISCUSSION}

This study investigates the potential of chemical treatment which is mild acid treatment in extracting the glucose from the kenaf biomass which used as the raw material. Two factors have been chosen for the optimization of chemical treatment which are mixing time and temperature in order to maximize the amount of glucose conversion. In order to determine the maximum glucose conversion from kenaf biomass with optimum condition, the experiments were designed based on Central Composite Design (CCD) by Design Expert v6.0.8 software. The polynomial regression model relating the percentage of conversion (Y) with independent variables, mixing time (A) and temperature (B) is as follows:

$\mathrm{Y}=-13.9001+2.1586 \mathrm{~A}-0.0526 \mathrm{~B}-0.0282 \mathrm{~A}^{2}+7.8599 \times 10^{-4} \mathrm{~B}^{2}-0.0126 \mathrm{AB}+1.6667$ $\times 10^{-4} \mathrm{~A}^{2} \mathrm{~B}$

where $\mathrm{Y}=$ the predicted of glucose content

The average amount of glucose content of duplicate values obtained was taken as observed amount of glucose content. All the variables, observed and predicted results are recorded in Table 1.

Table 1: Values of observed and predicted of response

\begin{tabular}{|l|l|l|l|l|}
\hline Run & Mixing Time & Temperature $\left({ }^{\circ} \mathrm{C}\right)$ & Glucose $(\mathrm{g} / \mathrm{L})$ & \\
\cline { 4 - 5 } & $(\mathrm{min})$ & & Actual & Predicted \\
\hline 1 & 30.00 & 180.00 & 0.366 & 0.555176 \\
\hline 2 & 60.00 & 180.00 & 0.754 & 0.944114 \\
\hline 3 & 30.00 & 160.00 & 0.334 & 0.238706 \\
\hline 4 & 45.00 & 200.00 & 0.457 & 0.64638 \\
\hline 5 & 45.00 & 180.00 & 0.388 & 0.355657 \\
\hline 6 & 60.00 & 200.00 & 3.397 & 3.30231 \\
\hline 7 & 45.00 & 180.00 & 0.439 & 0.355657 \\
\hline 8 & 30.00 & 200.00 & 0.374 & 0.27843 \\
\hline 9 & 60.00 & 160.00 & 0.531 & 0.436694 \\
\hline 10 & 45.00 & 180.00 & 0.620 & 0.355657 \\
\hline 11 & 45.00 & 160.00 & 0.504 & 0.693713 \\
\hline
\end{tabular}

The determination coefficient $\left(R^{2}=0.904\right)$ in this study specifies high correlation between the observed and predicted values and indicates the level of precision with which the glucose content is attributed to the independent variables, mixing time and temperature. This sample of variation implies that only $90.4 \%$ of glucose content was contributed to the independent variables meanwhile another $9.6 \%$ of the total variable cannot be explained by the model. The analysis of variance (ANOVA) is presented in Table 2. From this table, it shows that the model is significant ( $p$ value is 0.0480 ) and the Lack of Fit is also significant which is 0.0394 and the $\mathrm{R}^{2}$ for this analysis is $90.45 \%$. 
Table 2: ANOVA for response surface quadratic model

\begin{tabular}{|l|l|l|l|l|l|}
\hline Sources & $\begin{array}{l}\text { Sum of } \\
\text { Squares }\end{array}$ & $\begin{array}{l}\text { Degree } \\
\text { Freedom }\end{array}$ & $\begin{array}{l}\text { Mean } \\
\text { Square }\end{array}$ & F Value & $\begin{array}{l}\text { p-Value } \\
\text { (Prob> F) }\end{array}$ \\
\hline Model & 7.15 & 6 & 1.19 & 6.31 & $0.0480^{*}$ \\
\hline $\mathrm{A}$ & 2.17 & 1 & 2.17 & 11.49 & $0.0275^{*}$ \\
\hline $\mathrm{B}$ & $1.105 \mathrm{E}-003$ & 1 & $1.105 \mathrm{E}-003$ & $5.848 \mathrm{E}-003$ & 0.9427 \\
\hline $\mathrm{A}^{2}$ & 0.39 & 1 & 0.39 & 2.08 & 0.2226 \\
\hline $\mathrm{B}^{2}$ & 0.25 & 1 & 0.25 & 1.33 & 0.3137 \\
\hline $\mathrm{AB}$ & 2.00 & 1 & 2.00 & 10.57 & $0.0313^{*}$ \\
\hline $\mathrm{A}^{2} \mathrm{~B}$ & 0.75 & 1 & 0.75 & 3.97 & 0.1171 \\
\hline Residual & 0.76 & 4 & 0.19 & & \\
\hline Lack of Fit & 0.73 & 2 & 0.36 & 24.41 & 0.0394 \\
\hline Pure Error & 0.030 & 2 & 0.015 & & \\
\hline Cor Total & 7.91 & 10 & & \multicolumn{2}{l|}{} \\
\hline
\end{tabular}

From the statistical analysis which is in Table 2, the variable that give significant model or results are the linear effect of mixing time (A) and also the interaction between mixing time and temperature (AB). Since the linear and the interaction of mixing time gives significant results so it can be considered as the limiting factors and a little variation in this mixing time value, it will give great affect to entire results which is in glucose production. From Table 1, it shows the maximum glucose content is produced in Run 6 which is 3.397 $\mathrm{g} / \mathrm{L}$ (observed value) and it also shows the predicted value is quite similar withe the predicted value which is $3.30231 \mathrm{~g} / \mathrm{L}$. The Run 6 shows optimum condition when the mixing time is 60 minutes and the temperature is at $200{ }^{\circ} \mathrm{C}$. Chemically, the treatment process using dilute $\mathrm{H}_{2} \mathrm{SO}_{4}$ allow the microorganism exhibit the complex structure of kenaf biomass as lignocellulosic materials and break the complex structure into the simple sugars which can be consumed by microorganisms. By referring to the optimization chemical treatment's results, the higher the heating rate (mixing time and temperature), the easiest the separation of the carbohydrates from the lignin matrix of kenaf biomass. Thus, it will lead to the lowest chemical destruction of fermentation sugars which required for any end products like ethanol or lactic acid production. 

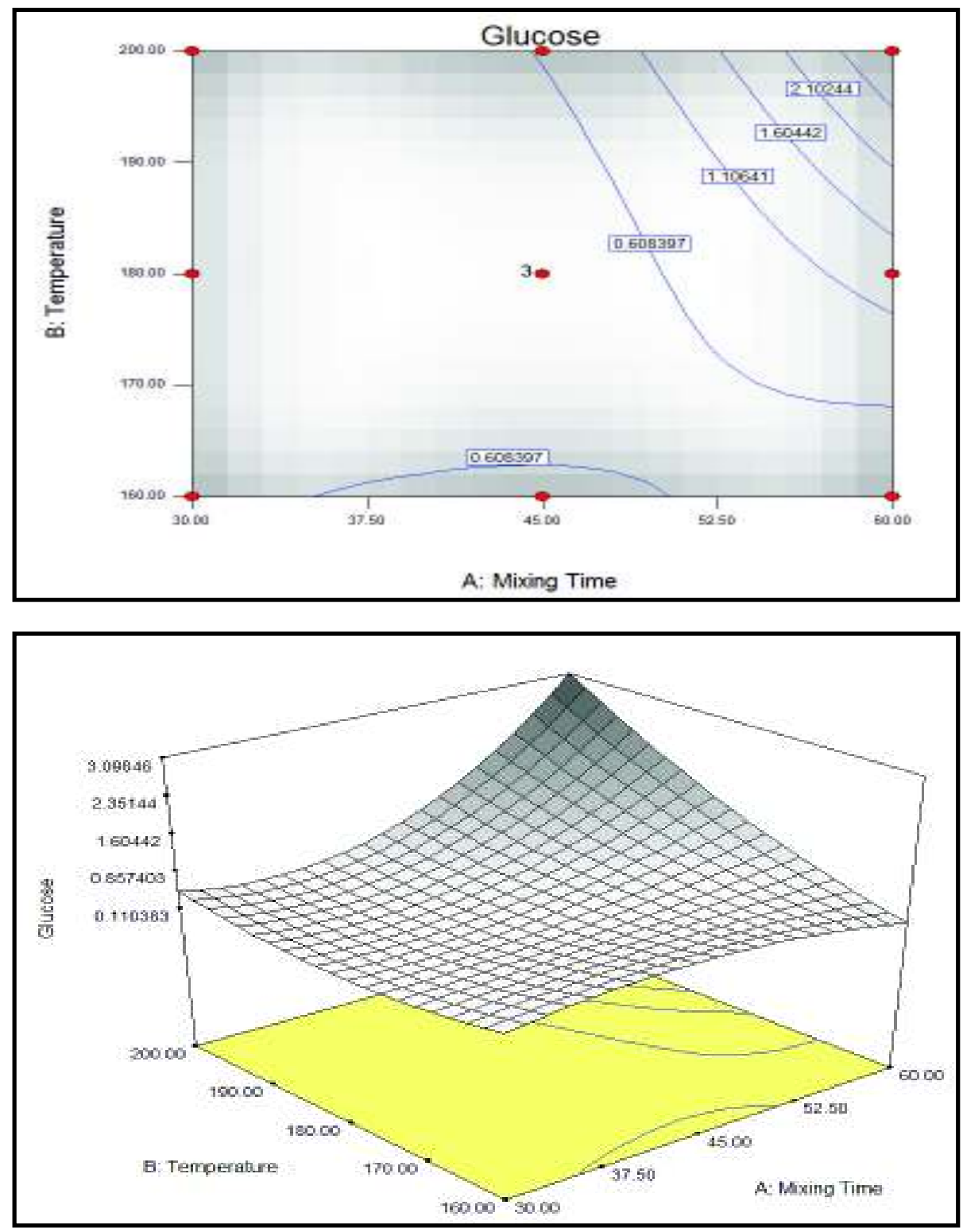

Figure 1: 2D contour plots and 3D response surface shows the effect of time (min) and temperature $\left({ }^{\circ} \mathrm{C}\right)$ on the glucose concentration (mass of fiber was $3 \mathrm{~g}$ and agitation speed was $100 \mathrm{rpm}$ ).

In order to determine the optimum values of variables, 3D surface and 2D contour plots are used as the graphical representation of the regression equation (Tanyildizi et al., 2005) as shown in Figure 1. The ultimate objective of the response surface is to investigate the optimum values of the variables such as the response is maximized (Tanyildizi et al., 2005). 
In $2 \mathrm{D}$ plot, each contour curve signify the infinity number of two variables with the other three remain at their respective zero level. The smallest ellipse from the confined surface in the contour plot are used to indicate the maximum predicted value. The perfect interaction between the independent variable will results an elliptical contour (Muralidhar et al., 2001). Figure 1 illustrate the response surface of the model equation in order to estimate glucose conversion over mixing time time and temperature. The $3 \mathrm{D}$ surface plot was described by the regression model in order to illustrate the effects of the independent variables and the combined effects of each independent variable upon the response variable (Duta et al., 2006). It can be observed that the high percent conversion was achieved at highest time and temperature. According to Xiang et al.(2003), the hydrogen bonding in the hemicellulose and cellulose fraction are easily break down at high temperature compare to low temperature which results to high yield of glucose.

\section{CONCLUSIONS}

This study established that the best chemical treatment condition for optimization of high yield total glucose content from kenaf biomass was obtained at $200{ }^{\circ} \mathrm{C}$ temperature and 60 minutes mixing time with total glucose content of $3.4 \mathrm{~g} / \mathrm{L}$.

\section{ACKNOWLEDGMENTS}

Exclusive thanks to COMSTECH-TWAS for funding this research. Not to forget, thank to the staff of Department of Biotechnology and Department of Manufacturing and Materials Engineering as a whole and technical assistance of Kulliyyah of Architecture and Environmental design for the laboratory analysis 


\section{REFERENCES}

BANERJEE, S., MUDLIAR, S., GIRI, B., SATPUTE, D., CHAKRABARTI, T., \& PANDEY, R. A. (2010).Commercializing lignocellulosic bioethanol: Technology bottlenecks and possible remedies. Biofuels, Bioproducts \& Biorefining, 4, 77-93.

DUTA, F. P., DE FRANCA, F. P., AND LOPES, L. M. D. A. 2006. Optimization of culture conditions for exopolysaccharides production in Rhizobium sp. using the response surface method. Journal of Biotechnology, 9(4), 391399.

HAMELINCK, C. N., HOOIJDONK, G., \& FAAIJ, A. P. C. 2005. Ethanol from lignocellulosic biomass: Techno-economic performance in short-, middle- and longterm. Biomass and Bioenergy, 28, 384-410.

KLINKE, H. B., THOMSEN, A. B. \& AHRING, B. K., 2004. Inhibition of ethanol - producing yeast and bacteria by degradation products produced during pre-treatment of biomass. Appl Microbiol Biotechnol $66,10-26$.

MAYA, J.J, \& SABU, T. 2008. Review Biofibres and biocomposite. Carbohdyrate Polymer, 71, 343-364.

MCMILLAN, J.D., 1994. Pretreatment of lignocellulosic biomass. In:Himmel, M.E., Baker, J.O., Overend, R.P. (Eds.), Enzymatic Conversion of Biomass for Fuels Production. American Chemical Society, Washington, DC, pp. 292-324.

MURALIDHAR, R. V., CHIRUMAMILA, R. R., MARCHANT, R., AND NIGAM, P. 2001. A response surface approach for the comparison of lipase production by Candida cylindracea using two different carbon sources. Biochem Eng J., 9, 17-23.

REN, H., HUANG, H.Z. \& ZHENG, J. 2009. Detoxifying and Recylcing of Washing Solution UsedIn Pretreatment Of Lignocellulose-Containing Materials. [http://www.faqs.org/patents/app/20090056889]. [Accessed on 27 February 2010]

SCOTT K, FLORES DM, KOBAYASHI G, SONOMOTO K. (2007) Direct Llactic acid fermentation with sago starch by a novel amylolytic lactic acid bacterium, Enterococcus faecium. Enzyme and Microbial Technology, 41(1-2):149-155. 
SUN,Y. \& CHENG, J. 2002. Hydrolysis of lignocellulosic materials for ethanol production: are view. Bioresource Technology 83, 1-11

TANYILDIZI, M. S., OZER, D., AND ELIBOL, M. 2005. Optimization of $\alpha-$ amylase production by Bacillus sp. using response surface methodology. Process Biochemistry, 40(7), 2291-2296.

XIANG, Q., LEE, Y. Y., PETTERSSON, P. O.,\& TORGET, R. W. (2003). Heterogeneous aspects of acid hydrolysis of cellulose. Applied Biochemistry and Biotechnology, 105-108, 505-514. 